\title{
Reflexões sobre "a mulher", o olhar e a questão racial na teoria feminista do cinema
}

\section{Reflections about "the woman", the look and the racial question in the feminist film theory}

Ceiça Ferreira

Universidade Estadual de Goiás - UEG.

<ceicaferreira@gmail.com>

\section{RESUMO}

Desde os anos de 1970, as representações das mulheres no cinema tem sido objeto de crítica das teóricas feministas, que destacam a relevância do cinema narrativo clássico como produto e produtor do imaginário patriarcal. Contudo, ancorada numa perspectiva psicanalítica, essa vertente teórica apresenta algumas limitações, como a ênfase na mulher branca como modelo de feminilidade e a construção binária do prazer visual. Neste artigo, a partir de estudos que discutem a experiência histórica das mulheres negras, busca-se problematizar a intersecção de gênero e raça como determinante nos sistemas de representação, na construção do prazer visual e nos modos de recepção fílmica, o que indica novas possibilidades para o reconhecimento das mulheres negras na teoria feminista do cinema.

Palavras-chave: Teoria feminista do Cinema. Mulheres negras. Gênero e raça.

\begin{abstract}
Since the 1970s, the representations of women in the cinema have been object of criticism of the feminist theorists, that emphasize the relevance of the classic narrative cinema as product and producer of the patriarchal imaginary. However, anchored in a psychoanalytic perspective, this theoretical aspect presents some limitations, such as the emphasis on the white woman as model of femininity and the binary construction of visual pleasure. In this article, based on studies that discuss the historical experience of black women, we seek to problematize the intersection of gender and race as determinant in the systems of representation, in the construction of visual pleasure and in modes of filmic reception, which indicates new possibilities for the recognition of black women in the feminist film theory.
\end{abstract}

Keywords: Feminist film theory. Black women. Gender and Race.

\section{Introdução}

Do cinema narrativo clássico emergiram imagens de mulheres íntegras e devassas, mães devotadas, esposas exemplares, heróis valentes e charmosos, estrelas e divas, mocinhas virtuosas e sonhadoras, vilões e mocinhos em busca de aventuras. Essas representações continuam a ser construídas e reelaboradas pelas narrativas filmicas, que têm como fonte principal o modelo hollywoodiano clássico. Trata-se de uma engrenagem meticulosamente organizada, que por meio da aplicação sistemática de normas, princípios e convenções técnicas, estéticas e narrativas atualiza referências da literatura, dos contos populares e do 
melodrama com certas regras de representação, como a estética na construção dos cenários e figurinos, na iluminação, no som e na interpretação dos atores.

O desenrolar da trama de forma linear e contínua e a construção das personagens são subordinados a uma estrutura de causa-efeito, que visa à verossimilhança, à clareza e à decupagem clássica. Tais procedimentos são capazes de dar a impressão de que a história se conta sozinha, incitando a identificação de quem assiste com as personagens, seus dilemas, conflitos e desejos, suas jornadas rumo à resolução dos problemas, bem como encantar-se com a magia dessa fábrica de sonhos (Bordwell, 2005; Xavier, 2005).

O melodrama, gênero dramático presente na literatura, no teatro e no folhetim, caracteriza-se por explorar temas de apelo emocional e por apresentar uma função moralizante, além de refletir os valores burgueses do século XIX, em que a família ocupa um lugar central na ordem patriarcal. Tal modelo foi retomado pelo cinema hollywoodiano e se tornou o paradigma maior da cultura de massa, tendo sido posteriormente explorado também na ficção televisiva e constituído uma fonte de representações que marcou o imaginário de todo o século XX. Por meio da estética naturalista, o melodrama, comumente associado ao público feminino, veicula os valores civilizatórios ocidentais e a ideologia patriarcal que opera na dicotomia do público versus privado e incute como norma a feminilização da família e da esfera doméstica (Hayward, 2000; Kaplan, 1995; Xavier, 2003).

A estrutura, os códigos e as representações que constituem o cinema narrativo clássico como uma prática cultural são objetos de análise e crítica da teoria feminista do cinema (feminist film theory), um vasto campo de estudos que busca desmistificar as relações de poder, o desejo e prazer visual, a objetificação feminina e as estratégias narrativas e estéticas por meio das quais são veiculados valores e padrões de comportamento. Contudo, se nos estudos pioneiros, publicados nos anos de 1970, sobressaía a ênfase na diferença sexual, em virtude da teoria psicanalítica utilizada como ferramenta para analisar o imaginário patriarcal, nas décadas seguintes, a própria teoria feminista do cinema passa a ser questionada.

Diante de críticas e reinterpretações, as assimetrias de gênero e suas intersecções com raça, etnia, classe e sexualidade passaram a ser consideradas no debate. Logo, buscando reconstruir os aspectos centrais desse percurso teórico, este trabalho problematiza as principais contribuições da crítica feminista do cinema (em especial o trabalho pioneiro de Laura Mulvey) e também suas limitações, a partir de estudos que discutem a experiência histórica das mulheres negras nos sistemas de representação e nas práticas de recepção e as formas 
de espectatorialidade, que possibilitam a emergência de outras problemáticas para a compreensão dos filmes de maneiras diferenciadas.

\section{A psicanálise como metodologia de análise do cinema}

$\mathrm{O}$ artigo "Visual pleasure and narrative cinema" ("Prazer visual e cinema narrativo"), da teórica e cineasta feminista britânica Laura Mulvey, publicado em 1975 na revista Screen é considerado um dos mais importantes textos da teoria feminista do cinema. A autora propõe o uso político da psicanálise como ferramenta metodológica para decifrar a fascinação, a magia do cinema clássico, que reflete em sua estrutura narrativa a diferenciação sexual socialmente estabelecida e incide sobre os processos de subjetivação dos indivíduos.

A partir de conceitos de Freud e Lacan, Mulvey busca desmistificar as construções binárias que, na narrativa cinematográfica, instituem o masculino como ativo e o feminino como passivo e naturalizam as assimetrias entre os gêneros também nas formas de ver e nos prazeres visuais. Tais hierarquias são construídas no inconsciente da sociedade patriarcal e falocêntrica por meio do complexo de Édipo, conceito freudiano que, inspirado no mito grego ${ }^{1}$, designa o processo de desenvolvimento da identidade sexual masculina, ou seja, quando o menino, que até então se vê ligado à mãe e não a reconhece como Outro (fase pré-edipiana), ao passar para a fase fálica toma consciência do pai e descobre que a mãe é castrada, não tem pênis. Essa dolorosa descoberta leva-o a se identificar com o pai e a se afastar da mãe, com medo da castração (Kaplan, 1995).

Diante dessa ameaça da castração é que se constrói a dupla função da mulher na formação do inconsciente patriarcal, oscilando, segundo Mulvey (1983), entre essa falta e a plenitude maternal, que implica introduzir seu filho na ordem simbólica. Assim, a figura feminina está restrita à castração, só existe como significante do outro masculino, "[...] é portadora de significado e não produtora de significado [...]" (Mulvey, 1983, p. 438). Tal relação assimétrica codifica as formas de prazer visual no cinema, pois a posição do/da espectador/a na sala escura suscita a escopofilia (ou o voyeurismo), descrita por Freud como o desejo/prazer de ver sem ser visto, e se completa com o exibicionismo feminino, definido pelo teórico como o desejo/prazer de ser visto.

Num mundo governado por um desequilíbrio sexual, o prazer no olhar é dividido entre ativo/masculino e passivo/feminino. O olhar masculino determinante projeta sua fantasia na figura feminina,

1 Escrito por Sófocles, este mito refere-se à história de Édipo, que inadvertidamente mata o pai, casase com a mãe e, consequentemente, é rigidamente punido. 
estilizada de acordo com essa fantasia. Em seu papel tradicional exibicionista, as mulheres são simultaneamente olhadas e exibidas, tendo sua aparência codificada no sentido de emitir um impacto erótico e visual de forma a que se possa dizer que conota a sua condição de "para-ser-olhada". A mulher mostrada como objeto sexual é o leitmotiv do espetáculo erótico [...] (Mulvey, 1983, p. 444).

Essa objetificação feminina é fundamental segundo a autora, tanto para o espetáculo quanto para a estrutura narrativa de um filme, já que as mulheres são utilizadas para promover a contemplação erótica (por meio de planos estáticos, closes) e estão sempre numa posição passiva - "[...] parecem sempre estar à espera de serem 'salvas [...]"' (Oliveira Filho, 2012, p. 41). Em contraponto, o homem, que além de portador do olhar é o sujeito da ação, tem um papel ativo no desenrolar dos acontecimentos, no avançar da narrativa, características que conduzem quem assiste à identificação com o protagonista masculino e sua posição de poder. Também por meio desse processo é possível indiretamente possuir a personagem feminina, que funciona como objeto erótico em dois níveis: para as personagens da trama e para o/a espectador/a que está no público, fazendo interagir os olhares de ambos os lados da tela.

Todavia, uma vez que mesmo na condição de objeto a mulher ainda conota a ameaça da castração, o inconsciente masculino desenvolveu no cinema dois mecanismos para escapar dessa ansiedade: 1 - a ênfase nesse trauma original (a castração) ao tentar investigar e decifrar o mistério feminino, articulada à sua desvalorização, ao colocá-la na posição de alguém que deve ser salvo ou punido (para isso utiliza o voyeurismo e o sadismo para conquistar um prazer que se constrói por meio da determinação da culpa), ou seja, submete a figura feminina à punição ou ao perdão; 2 - a completa rejeição da castração, substituindo ou transformando a figura feminina por/em um fetiche, bastante visível no culto das estrelas de cinema (consideradas egos ideais), expressões da escopofilia fetichista (Maluf; Mello; Pedro, 2005; Mulvey, 1983).

Ainda sobre o olhar no cinema clássico, a autora ressalta que existem três tipos: o olhar da câmera, sem a intervenção da montagem (um olhar anterior ao produto final do cinema); o olhar dos/das espectadores/as, que veem o produto final; o olhar dos atores entre si dentro da ilusão projetada. As convenções da narrativa clássica, ao enfatizar o terceiro olhar e rejeitar os dois primeiros reiteram a montagem invisível e seu objetivo na identificação, já que direcionam a atenção para o enredo, para as ações das personagens (construídas a partir de uma visão dicotômica das relações de gênero, que transita entre a linguagem cinematográfica e o imaginário de quem os assiste). 
Em contraponto ao cinema narrativo clássico, Mulvey propõe a criação de um contracinema, um cinema alternativo, político e estético, capaz de romper, destruir os prazeres visuais codificados pela narrativa clássica dentro da ordem patriarcal. Isso se mostra possível, segundo Oliveira Filho (2012), a partir do uso de recursos como o plano-sequência, a exposição do aparato técnico e da equipe de filmagem indicando o processo de fabricação do filme, bem como uma postura que flexibiliza o trabalho de direção; e, principalmente, uma perspectiva feminista, já que se centra, sobretudo, no protagonismo das mulheres em suas diferentes formas de luta contra a cultura falocêntrica. Exemplo dessa proposta são os próprios filmes de Laura Mulvey, como o documentário Frida Kahlo \& Tina Modotti (1983), dirigido com Peter Wollen e que evidencia seu propósito de desconstruir a estética naturalista do cinema clássico e sua construção do prazer visual.

Embora sejam amplamente reconhecidas as contribuições de Mulvey, que a tornaram referência na teoria feminista do cinema, também é dentro desse campo de estudo que foram elaboradas novas e diferentes leituras e críticas. Estas apontaram "[...] as limitações ideológicas do freudianismo, com seu privilégio do falo, do voyeurismo masculino e do cenário edipiano, que deixavam pouco espaço para a subjetividade feminina [...]" (Stam, 2003, p. 197), tanto na representação quanto na recepção, já que ignorava as possibilidades de subversão e redirecionamento do olhar masculino pelas personagens femininas tanto na narrativa quanto por parte das espectadoras, ao encaixá-las em um molde masculino.

A própria Mulvey $(2005)^{2}$ reavalia seu modelo analítico, reconhece a ênfase no olhar masculino como uma limitação e acrescenta à argumentação anterior duas questões que havia desconsiderado: as "mulheres do público" e o "melodrama". A partir daí ela analisa os filmes Duelo ao sol e Stella Dallas, do cineasta King Vidor, e recorre à teoria freudiana sobre a feminilidade e a libido, que se dá numa fase pré-simbólica e ativa do desenvolvimento da sexualidade, para compreender a indecisão das protagonistas diante das possibilidades colocadas pelos personagens masculinas: decidir por um destino estável, o casamento, ou negá-lo a partir de uma vida de aventura.

As personagens femininas ainda se mantem atreladas ao olhar masculino, porém quando essa mulher é vista a partir do público, o determinismo do "olhar masculino" é quebrado e se torna uma posição, um ponto de vista, o que possibilita à espectadora assumi-lo. Logo, tem-se aqui um deslocamento de

2 O artigo "Reflexões sobre 'Prazer visual e cinema narrativo' inspiradas por Duelo ao Sol, de King Vidor (1946)" foi publicado originalmente em 1989 e traduzido no Brasil somente em 2005. 
uma visão monolítica da identificação para uma perspectiva mais ampla, a das posicionalidades, que significa, sobretudo, a possibilidade de negociação por parte da espectadora.

\title{
A diferença sexual e o privilégio branco: limites da teoria feminista do cinema
}

Embora Laura Mulvey tenha repensado sua teoria do prazer visual, conforme mencionado acima, suas formulações ainda se sustentam na teoria psicanalítica e na diferença sexual, instigando também críticas de outras teóricas feministas. Um dos primeiros trabalhos a discutir as limitações do quadro conceitual da psicanálise é o de Jane Gaines (1999).

\begin{abstract}
A oposição masculino/feminino, aparentemente tão fundamental para o feminismo, pode realmente nos bloquear em modos de análise que irão continuamente mal interpretar a posição de muitas mulheres. Deste modo é que as mulheres não-brancas, assim como as lésbicas, enquanto uma reflexão tardia na análise feminista, permanecem não assimiladas por esta problemática. Antologias feministas incluem consistentemente artigos sobre a mulher negra e perspectivas lésbicas como ilustração da liberalidade e inclusão do feminismo; no entanto, o próprio conceito de "perspectivas diferentes", ao validar a distinção e manter a mulher como denominador comum, ainda coloca as categorias de raça e orientação sexual no limbo teórico (Gaines, 1999, p. 294, tradução nossa). ${ }^{3}$
\end{abstract}

Ao centrar-se numa perspectiva geral, a teoria feminista do cinema mostra-se incapaz de lidar com a história e a experiência das mulheres como sujeitos históricos. A compreensão do regime escravista possibilitaria, de acordo com a autora, indagar, por exemplo, a posição da personagem masculina negra como superior à personagem feminina negra, mas que não lhe permite a posição de controle ocupada pelo homem branco, o sujeito do olhar e da ação. Logo, "[...] raça pode ser um fator na construção da linguagem cinematográfica [...]" (Gaines, 1999, p. 301, tradução nossa) ${ }^{4}$, bem como possibilita reconhecer a histórica exclusão da mulher negra dos processos de representação e até

3 No original: The male/female opposition, seemingly so fundamental to feminism, may actually lock us into modes of analysis which will continually misinterpret the position of many women. Thus it is that women of colour, like lesbians, an afterthought in feminist analysis, remain unassimilated by this problematic. Feminist anthologies consistently include articles on black female and lesbian perspectives as illustration of the liberality and inclusiveness of feminism; however, the very concept of 'different perspectives', while validating distinctness and maintaining woman as common denominator, still places the categories of race and sexual preference in theoretical limbo. Our political etiquette is correct, but our theory is not so perfect (Gaines, 1999, p. 294).

4 No original: [...] race could be a factor in the construction of cinematic language (Gaines, 1999, p.301). 
mesmo da condição de feminilidade, esta que, dentro da cultura americana, tem sido comumente definida como a feminilidade branca, o que bloqueia a percepção de formas diferenciadas de lidar com o corpo e a sexualidade.

Nesse sentido, a autora pontua que, enquanto as feministas brancas teorizam a imagem feminina em termos de objetificação, as feministas negras problematizam o corpo feminino negro como um lugar de resistência simbólica em contraposição ao "paradoxo do não ser", conceito elaborado pela crítica literária Hortense Spillers e que designa a desumanização no regimeescravocrata, no qual a mulher negra não existia, não era considerada uma "mulher". Por tais razões, Gaines (1999) defende que a chave para entender o privilégio branco e as relações do olhar no cinema não são as categorias analíticas, são os discursos históricos e socioculturais específicos da escravidão e das relações raciais.

A partir de filmes populares, a teórica Tania Modleski (1999) também analisa a intersecção de gênero e raça na representação das mulheres negras como lócus para onde se direcionam os medos e as ansiedades da sociedade branca. Utilizando uma cena do filme A Vênus loira (Josef von Sternberg, 1932), na qual a protagonista Helen (interpretada pela atriz Marlene Dietrich) apresenta o número musical "Hot Voodoo" travestida de macaco, acompanhada por um grupo de mulheres de blackface ${ }^{5}$ com figurino e acessórios africanos (máscaras e lanças) em um cenário de selva (Figura 1), a autora argumenta que o racismo no filme não é incidente, já que tal sequência associa-se às personagens femininas negras (uma empregada [não identificada] e Cora, a dona de pensão vivida pela atriz Hattie McDaniel) presentes nos "locais exóticos" que a protagonista visita em sua viagem de fuga até Orleans, no estado de Louisiana (Figura 2).

5 O termo blackface designa uma técnica usada desde os primórdios do cinema, que consiste em colocar atores e atrizes brancas pintadas de preto para interpretar personagens negras. 
- Figura 1 - Helen (Marlene Dietrich) sob o olhar de Nick (Cary Grant) na apresentação musical "Hot Voodoo"
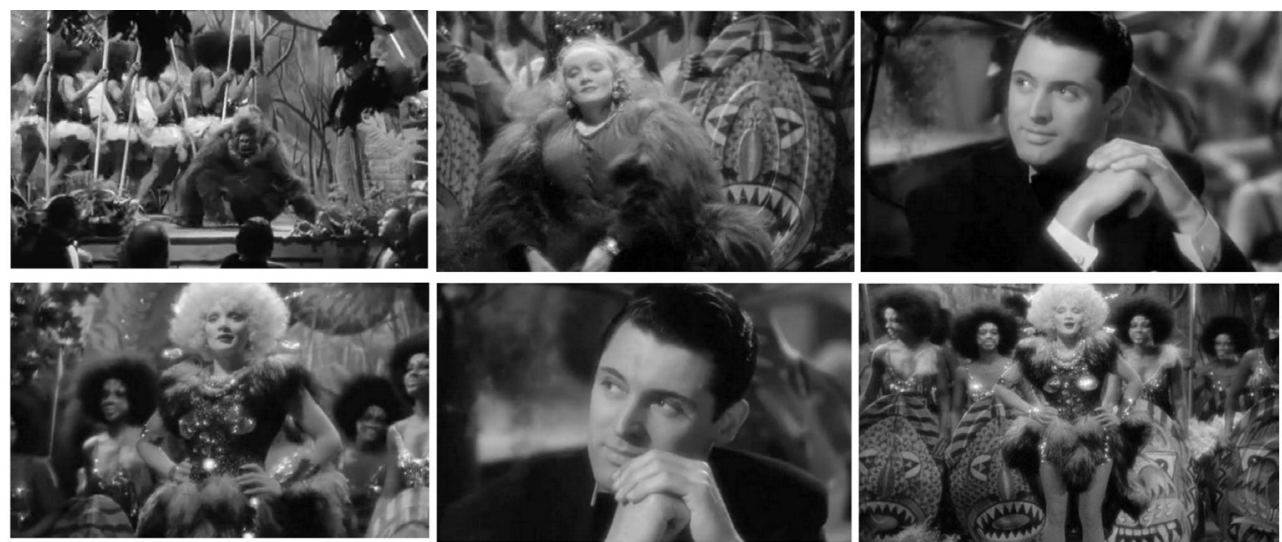

Fonte: Filme A Vênus Loura (Blonde Venus, Josef von Sternberg, 1932)

Figura 2 -Personagens femininas negras no filme $A$ Vênus loira (1932): Aempregada não identificada; B- Cora, dona de pensão (HattieMcDaniel)
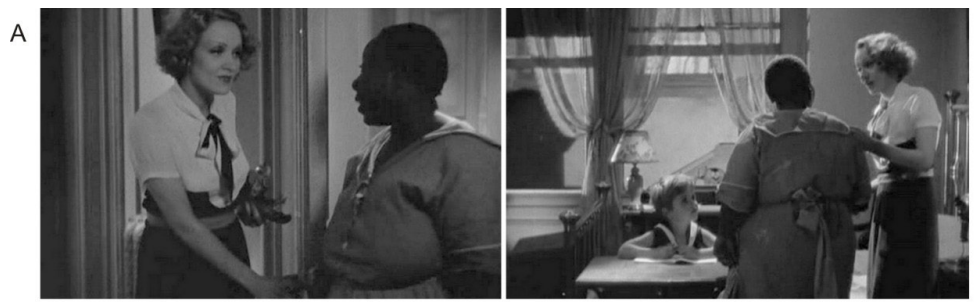

$B$
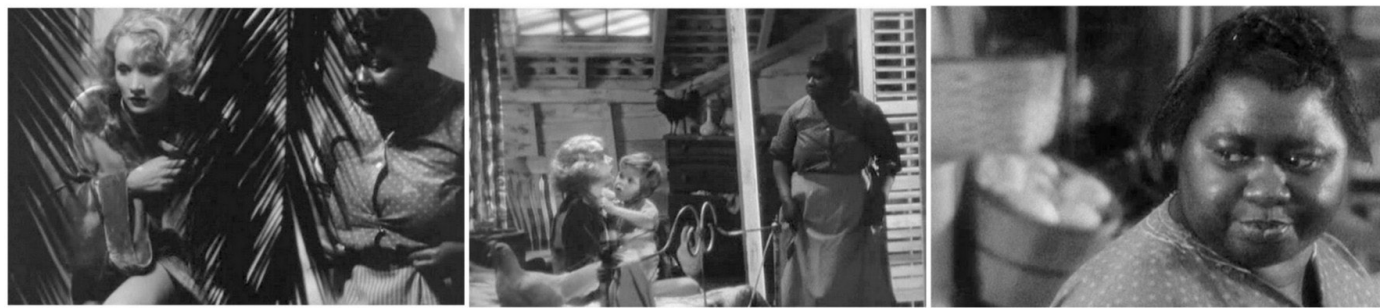

Fonte: Filme A Vênus Loura (Blonde Venus, Josef von Sternberg, 1932)

As duas atrizes que interpretam essas personagens secundárias não são creditadas no filme. Hattie McDaniel foi a primeira atriz negra a ganhar o Oscar. Em 1940, ela recebeu o prêmio de melhor atriz coadjuvante por sua atuação no filme ...E o vento levou (Gone with the Wind, Victor Fleming, 1939), no qual 
interpretou Mammy, a simpática e teimosa escrava da protagonista Scarlet O’Hara (Vivien Leigh), encarnando assim o estereótipo da Mammý.

Tais aspectos confirmam, segundo a autora, o trabalho fetichista de presença/ausência, diferença/semelhança, humano/animal na performance de "Hot Voodoo". Dietrich é o macaco, mas ela não é o macaco, já que se despe de sua fantasia (mantém apenas a peruca afro) e assume o lugar de destaque à frente das dançarinas caracterizadas de africanas. Considerando essa imagem como emblemática das complexas inter-relações de gênero e raça na representação popular, Modleski (1999) ressalta:

[...] nós somos forçados a reconhecer que, embora todo mundo neste cenário (exceto para o homem branco, interpretado por Cary Grant, que está olhando) é relegado ao "o lugar ideologicamente nomeado de estereótipo", as mulheres negras do filme estão na posição mais marginalizada. Se isso é verdade, para citar a célebre formulação de Claire Johnston ${ }^{7}$, a mulher como mulher foi praticamente inexistente no cinema patriarcal, este foi obviamente muito mais o caso das mulheres negras do que das brancas. E se a mulher branca tem servido geralmente como o significante do desejo masculino (que é o que Johnston quis dizer quando falou da ausência da mulher como mulher), a mulher negra, quando presente em tudo, tem servido como um significante da sexualidade feminina (branca) ou do corpo maternal ("Mammy") (Modleski, 1999, p. 329-330, tradução e grifo nossos). ${ }^{8}$

Essa asserção é confirmada pela autora na comédia romântica Crossing Delancey (Susan Sandler, 1988), na qual uma mulher negra gorda representa todos os desejos e medos que o filme nega: a sexualidade e a fome vorazes. Em um papel pequeno, a personagem feminina negra serve como contraponto à conduta sexual da mulher branca e como pano de fundo (metáfora espacial) na composição do quadro.

6 Um dos únicos papeis atribuídos às mulheres negras na Hollywood dos anos 1930, a Mammy designa, segundo Bogle (2006), uma empregada negra gorda, falante, rabugenta e, principalmente, afetuosa.

7 A teórica feminista Claire Johnston foi uma das pioneiras a analisar os estereótipos na representação das mulheres no cinema.

8 No original: [...] we are forced to recognize that while everyone in this scenario (except for the white male, played by Cary Grant, who is looking on) is relegated to 'the ideologically appointed place of the stereotype, the black women in the film are in the most marginalized position. If it is true, to cite Claire Johnston's famous formulation, woman as woman has largely been absent from patriarchal cinema, this has obviously been much more literally the case for black women than for whites. And if the white woman has usually served as the signifier of male desire (which is what Johnston meant when she spoke of the absence of woman as woman), the black woman, when present at all, has served as a signifier of (white) female sexuality or of the maternal ('Mammy') (MODLESKI, 1999, p. 329-330). 
Além do "outro" sexual, a mulher negra também é reduzida a significante de significante; de acordo com Modleski, como o corpo maternal, "substituto psíquico da mãe, como a Mammy", conforme se evidencia na personagem da atriz Whoopi Goldberg no filme Clara's heart (O coração de Clara, Robert Mulligan, 1988). A partir da relação afetiva entre essa personagem negra (uma empregada de origem jamaicana) e um menino branco, a pesquisadora pontua também uma dimensão sexual, problematizada com base na psicanálise, na teoria feminista e nas reflexões feministas negras nos Estados Unidos, estas que investigam o imaginário colonial/patriarcal suscitado na metáfora "continente negro", usada por Freud para descrever a sexualidade feminina (branca) como desconhecida aos homens.

A recente teoria feminista tem mostrado que a babá na concepção de Freud desempenhou um importante, ainda que amplamente não reconhecido, papel na iniciação da criança no conhecimento sexual. Nos Estados Unidos, como as feministas negras têm apontado, a mulher negra tem frequentemente exercido não apenas uma função similar na aculturação das crianças brancas. Clara's Heart, estrelado por Whoopi Goldberg, fornece uma ilustração invulgarmente decisiva do processo pelo qual o jovem branco atinge a maturidade penetrando o mistério da mulher negra, "sua sabedoria, seu calor, seu segredo", como anuncia o cartaz. O fato (retornando à metáfora do continente negro) de que estamos lidando aqui quase literalmente com o "coração das trevas" é sugerido pelo último nome de Clara [o filme], em que o 'Coração' é um órgão que acaba por ser um eufemismo para uma parte do corpo mais libidinalmente catexizada (Modleski, 1999, p. 331, tradução nossa). ${ }^{9}$

Ainda sobre a atuação de Whoopi Goldberg no cinema, Modleski analisa sua personagem no filme Ghost (Ghost: do outro lado da vida, Jerry Zucker, 1990), no qual a atriz interpreta a médium Oda Mae Brown. Esta, ao promover o reencontro do espírito de Sam (Patrick Swayze) com sua esposa Molly (Demi Moore), literalmente serve à função de incorporação: "A câmera mostra um closeup das mãos da mulher negra até alcançarem as da mulher branca, e então corta

9 No original: Recent feminist theory has shown that the nursery maid in Freud's own time played an important, although largely unacknowledged, role in initiating the child into sexual knowledge. In America, as black feminists have pointed out, the black woman has more often than not served a similar function in the acculturation of white children. Clara's Heart, starring Whoopi Goldberg, provides an unusually stark illustration of the process whereby the young white male achieves maturity through penetrating the mystery of the black woman 'her wisdom, her warmth, her secret, as the poster proclaims. That (returning to the metaphor of the dark continent) we are dealing here almost literally with the 'heart of darkness' is suggested by Clara's last name, which 'Heart' an organ that turns out to be a euphemism for a more libidinally cathected body part (MODLESKI, 1999, p.331). 
para uma tomada não de Oda Mae, mas de Sam, que ao assumir o corpo dela apagou sua presença inteiramente" (Modleski, 1999, p. 332, tradução nossa) ${ }^{10}$.

Essa sequência em que a personagem de Whoopi se transforma em um homem demonstra, segundo a autora, uma continuidade dos papéis cômicos interpretados por essa atriz negra, "sempre codificada nas comédias como mais masculina do que feminina". Esse aspecto é recorrente nos filmes Jumping Jack Flash (Salve-se quem puder, Penny Marshall, 1986) e Fatal Beauty (Mercadores da morte, Tom Holland, 1987), nos quais sua performance, por meio do exagero e do embaraço com o figurino e uma postura tradicionalmente "feminina", levamna a ser confundida com uma travesti.

Tal corporeidade, que não se enquadra na ideia de uma feminilidade branca preestabelecida (Figura 3), poderia ser analisada, de acordo com a autora, a partir das formulações da filósofa Judith Butler como uma subversão das normas de gênero, ao romper com a compulsória coerência entre gênero, anatomia e performance. Contudo, Modleski (1999, p. 333, tradução nossa) argumenta que "[...] em certos casos, como os que envolvem a mulher não-branca, muitas vezes considerada, nas palavras de [Homi] Bhabha, 'não completamente' uma mulher, este tipo de 'jogo' pode ter implicações extremamente conservadoras [...]"11, pontuando assim a necessidade de se pensar a intersecção de gênero e raça.

10 No original: The camera shows a close-up of the black woman's hands as they reach out to take those of the white woman, and then it cuts to a shot not of Oda Mae but of Sam, who in taking over her body has obliterated her presence entirely (MODLESKI, 1999, p.332).

11 No original: [...] in certain cases, such as those involving the woman of color who has often been considered, in Bhabha's words, 'not quite' a woman, this kind of 'play' may have extremely conservative implications (MODLESKI, 1999, p.333). 


\section{Figura 3 - A atriz Whoopi Goldberg em quatro papéis cômicos}
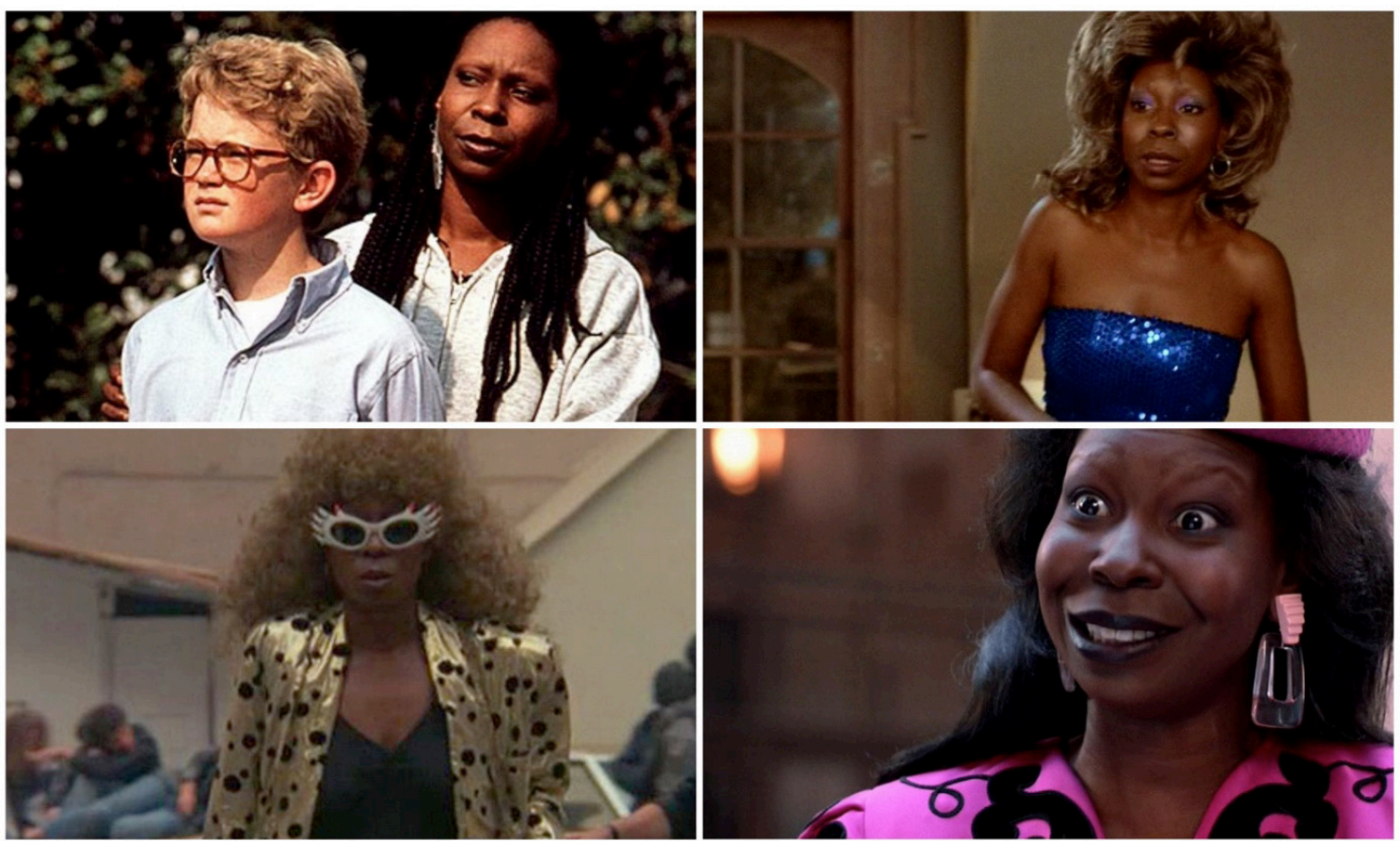

Fonte: Filmes Clara's Heart (Robert Mulligan, 1988), Jumping Jack Flash (Penny Marshall, 1986), Fatal Beauty (Tom Holland, 1987) e Ghost (Jerry Zucker, 1990)

Ao articular as duas formas pelas quais Whoopi é retratada nos filmes mencionados, como o corpo maternal/feminino (em Clara's Heart) e como mais ou menos masculino (nas comédias), Tania Modleski aponta uma ambígua continuidade histórica na representação da mulher negra:

Não estamos tão longe da situação abordada por SojournerTruth ${ }^{12}$ [...]. A mulher negra é vista tanto como muito literalmente uma mulher (reduzida à sua biologia e funções biológicas) ou, em aspectos cruciais, quanto como alguém que não é de modo algum uma mulher (Modleski, 1999, p. 333, tradução nossa). ${ }^{13}$

Aliadas a esse trabalho de desconstrução, a autora aponta ainda outras possibilidades de sentido das personagens cômicas de Whoopi, como uma

12 A autora refere-se ao discurso “Não sou uma mulher?" ("Ain't I a woman?"), de SojournerTruth (17971883), "nome adotado (a partir de 1843), por Isabella Baumfree, uma abolicionista afro-americana e ativista dos direitos da mulher. Truth nasceu no cativeiro em Swartekill, Nova York. Tal discurso foi pronunciado em 1851, na Convenção dos Direitos da Mulher na cidade de Akron, em Ohio" (Ribeiro, 2015, s/p).

13 No original: [...] we are not all that far from the situation addressed by Sojourner Truth [...]. The black woman is seen either as too literally a woman (reduced to her biology and her biological functions) or in crucial ways not really a woman at all. 
saída libertadora para as sufocantes convenções da feminilidade, o que também permite a essa atriz subverter as limitações das personagens ou explorar o potencial subversivo imerso no texto.

Também em consonância com os estudos citados, Mary Ann Doane (1991 citado por McCabe, 2004) discute uma espécie de "não lugar" que é conferido à mulher negra na teoria feminista, indicando as dificuldades teóricas de tal campo de estudo quanto à abordagem de gênero e raça.

[A] categoria de mulheres é geralmente usada para se referir a mulheres brancas, enquanto a categoria de negros, muitas vezes realmente significa "homens negros". O que se perde nesse processo é a situação da mulher negra. A posição dela torna-se bastante peculiar e opressivamente única: em termos de opressão, ela é tanto negra quanto uma mulher; em termos de teoria, ela não é nem um nem outro. Com efeito, ela ocupa uma posição que é difícil de pensar dentro de paradigmas atuais (Doane, 1991 citado por McCabe, 2004, p. 57 , tradução nossa) $)^{14}$.

Doane também explora a metáfora freudiana da feminilidade para investigar a complexa articulação das categorias de raça e diferença sexual, e assim relaciona-a com as representações artísticas e literárias produzidas pelo imaginário colonial que associam a mulher africana com o "continente negro", a partir do qual também o corpo das nativas era mapeado como local exótico/ erótico. Nesse sentido, Doane menciona os estudos de Sander Gilman ${ }^{15}$ sobre a forma como a mulher negra foi instituída como a representação da sexualidade promíscua no imaginário popular europeu do século XIX.

Nesse contexto histórico, tal pesquisador aponta a história de Sara Bartman $^{16}$, sul-africana da etnia khoi-san, mais conhecida como a Vênus Hotentote, que em virtude da protuberância de suas nádegas e genitália foi transformada na personificação da diferença, da alteridade, sendo atração em exibições públicas e "espetáculos" científicos. Construída sob o ponto de vista do homem branco europeu, que se impõe como a normalidade, essa representação de hipersexualidade primitiva e inferioridade racial foi usada para justificar

14 No original: [The] category of women is usually used to refer to white women, while the category of Blacks often really means 'Black men'. What is lost in the process is the situation of the Black woman. Her position becomes quite peculiar and oppressively unique: in terms of oppression, she is both Black and a woman; in terms of theory, she is neither. In effect, she occupies a position which is difficult to think within current paradigms (Doane, 1991 citado por McCabe, 2004, p. 57).

15 Doane cita o artigo "Black bodies, white bodies: toward an iconography of female sexuality in late nineteenth-century art, medicine and literature", de Gilman, publicado em 1985 na revista Critical Inquiry.

16 A história de Bartman foi recentemente retratada no filme Venus Noire (Vênus Negra, 2011), do diretor franco-tunisiano AbdellatifKechiche. 
o tratamento dado às mulheres negras, supostamente naturalizadas como amantes/concubinas e prostitutas (McCabe, 2004). Logo, essa articulação entre a história e a produção de imagens e discursos sobre raça e diferença sexual é apontado por Doane como fundamental para a teoria feminista do cinema, já que possibilita compreender como as ideologias raciais e sexuais estruturam as formas de representação e os modos de ver.

Em diálogo com tais formulações, a feminista negra Lola Young (1996a, 1996b) estuda a conexão de raça, gênero e sexualidade no cinema e na história britânicos, reconhecendo assim a centralidade da produção cultural na difusão das categorias raciais como instrumento de poder nos períodos colonial e póscolonial. Essa perspectiva interseccional fundamenta a crítica da autora à teoria feminista do cinema, em especial aos modelos de análise da mulher negra na cultura, que se centram sobre o racismo, mas não percebem sua intrínseca ligação com outras formas de opressão, como gênero e classe. Assim, a autora racionaliza alguns dos pressupostos de Laura Mulvey (1975) acerca das duas estratégias do inconsciente masculino para impedir a ameaça da castração no cinema.

A primeira consiste em investigar a personagem feminina, tentando decifrar seus mistérios e colocá-la numa posição que suscita punição. De acordo com Young (1996b), essa estratégia é conhecida das mulheres negras, que, a partir do século XIX, tiveram a anatomia de sua genitália sob constante e minuciosa análise no discurso médico e científico, tanto em público quanto em laboratório, conforme atesta o caso da Vênus Hotentote. Além disso, a autora elucida que, se as mulheres brancas podem ser punidas pelo desejo que suscitam, as negras são frequentemente punidas por meio de sua aniquilação simbólica e pelo status periférico de suas personagens.

A segunda estratégia é a transformação da figura feminina como fetiche, evidenciada no culto às estrelas de cinema. Explorando o caráter opressivo da noção de beleza feminina para as mulheres brancas, mas, principalmente, para as mulheres negras, por não possuírem o pré-requisito essencial para o ideal de beleza europeu, ou seja, a pele branca ressalta a pesquisadora:

Historicamente, as mulheres de ascendência africana nunca foram passíveis de "supervalorização" no mesmo sentido que as mulheres "brancas" têm sido, e comparativamente poucas podem ser descritas como sendo parte do "culto da estrela feminina". Imagens de mulheres europeias como padrão de beleza e desejabilidade são disseminadas, e poucas mulheres "brancas" parecem estar conscientes das maneiras pelas quais elas são representadas como o polo oposto - mas dependente - de concepções de sexualidade 
e feminilidade das mulheres negras (Young, 1996b, p. 190, tradução nossa) ${ }^{17}$.

Lola Young também problematiza essas assimetrias raciais a partir de Freud e identifica-as na personagem de Whoopi no filme Ghost. Ela indaga sobre o papel das mulheres negras como contraste à feminilidade branca (considerada a norma), bem como o status marginal (outsider) frequentemente atribuído a negros e negras, em decorrência dos estigmas de raça, gênero e classe.

Essa articulação é amplamente explorada, segundo a autora, na ênfase dos elementos corporais em detrimento da densidade psicológica; na recorrente caracterização cômica e infantilizante; na escassez de vínculos e relações de pertencimento das personagens; na associação entre negritude e pobreza, naturalizados como termos intercambiáveis. Young aponta alguns desses aspectos na personagem Oda Mae em razão das espacialidades por onde ela transita, seu figurino e performance corporal.

Como Oda Mae visualmente demonstra em sua caminhada pela cidade, do gueto ao distrito financeiro, ela está fora de lugar, não só em termos da sua sexualidade e sua "raça", mas também em termos de sua classe. Seu status de intrusa é significado através de sua roupa: o brilhante casaco fúcsia-rosa que ela usa contrasta com o cinza sombrio que as pessoas "brancas" usam e o desconforto causado pelos sapatos de salto e a saia justa a fazem caminhar de uma forma que se assemelha a de uma drag queen, sinalizando uma ansiedade com a postura de feminilidade (Young, 1996b, p. 195, tradução nossa) $)^{18}$.

A autora também enaltece as sutilezas da atuação de Whoopi, especialmente sua habilidade cômica, que Ihe permite subverter os roteiros, recuperar algum sentido nas personagens que comumente interpreta em

17 No original: Historically, women of African descent have never been subject to 'overvaluation' in the same sense that 'white' women have, and comparatively few may be described as being part of 'the cult of the female star'. Images of European women as the standard of beauty and desirability are pervasive, and few 'white' women seem to be aware of the ways in which they are imaged as the polar opposite of - yet dependent on - conceptions of Black women's sexuality and femininity (Young, 1996b, p. 190).

18 No original: As Oda Mae visually demonstrates on her walk across town from the ghetto to the financial district, she is out of place, not only in terms of her sexuality and her 'race' but also in terms of her class. Her intruder status is signified through her clothing: the bright fuschia-pink jacket she wears contrasts with the sombre greys that the 'white' people wear and the discomfort caused by the heeled shoes and pencil skirt make her walk in a way which resembles that of a female impersonator, signalling an anxiety with the posture of femininity (Young, 1996b, p. 195). 
comédias. Isso também no filme Ghost, no qual a atriz é capaz de fazer sua personagem se destacar do visual cinza e maçante do filme ${ }^{19}$.

Dessa forma, Lola Young reitera uma dupla necessidade de trabalhar a partir de um quadro conceitual capaz de reconhecer as intersecções entre gênero, raça e classe, bem como de examinar como a branquitude se manifesta no cinema, na televisão e na produção cultural como um todo, buscando assim não apenas expor o que está oculto, mas também repensar as posições teóricas que são construídas. Ela enfatiza que "um texto cinematográfico [...] deve ser analisado como parte de uma complexa teia de experiências, ideias e fantasias de desejo, ansiedade, medo e negação que estão inter-relacionadas e precisam ser localizadas em seus contextos históricos, políticos e sociais [...]" (Young, 1996b, p. 200, tradução nossa) ${ }^{20}$.

\section{O olhar e o prazer visual a partir da experiência histórica das mulheres negras}

A teórica feminista negra bell hooks ${ }^{21}$ (1992) afirma que a percepção das assimetrias de raça e gênero no cinema e nos meios de comunicação em geral fez as espectadoras negras rejeitarem tais representações. A partir de uma perspectiva distinta daquela defendida por Laura Mulvey (1975), ela desconstrói o olhar masculino no cinema como um dado universal e, considerando a experiência histórica diferenciada das mulheres negras, ressalta que raça também é determinante na construção do olhar e do prazer visual.

Considerado um instrumento de dominação, o olhar era negado a homens e mulheres negras escravizadas. Todavia, ancorando-se na perspectiva foucaultiana que compreende dominação em termos de relações de poder, também atravessadas por possibilidades de resistência, de agência, hooks (1992) destaca que essa relação traumática fez as mulheres negras desenvolverem em suas formas de espectatorialidade um olhar oposicional à maneira como são retratadas no cinema.

Tendo as mulheres negras como foco de sua análise, bell hooks acrescenta a categoria gênero para reflexão, tanto dos estudos sobre espectatorialidade

19 Por sua atuação nesse filme, Whoopi recebeu em 1991 o Oscar de melhor atriz coadjuvante. Ela foi a segunda atriz negra a receber essa que é considerada a maior premiação do cinema mundial.

20 No original: A cinematic text [...] should be analysed as part of a complex web of inter-related experiences and ideas, fantasies and experimental expressions of desire, anxiety, fear and denial that need to be located in their historical, political and social contexts (Young, 1996b, p. 200).

21 Pseudônimo da feminista negra estadunidense Gloria Jean Watkins. Ela assina bell hooks, propositalmente em letras minúsculas, e argumenta que o foco das pessoas deve estar no seu trabalho e não no seu nome. Em respeito às razões e convicções de sua escolha, mantemos neste artigo a grafia em caixa-baixa. 
negra (como o desenvolvido por Manthia Diawara sobre o poder do espectador negro em resistir à identificação com o cinema dominante) quanto da produção de cineastas negros que também compartilham essa postura de questionar as representações dominantes sobre raça, mas, conforme aponta a autora, raramente se preocupam com gênero.

Como espectadores, os homens negros viviam uma situação ambígua, pois embora contestassem a reprodução do racismo nos filmes, também poderiam, ao ousar olhar, envolver-se na política falocêntrica do espectador, sentir como se estivessem se rebelando contra a supremacia branca, já que o espaço privado do cinema Ihes possibilitava olhar a feminilidade branca sem o controle e, principalmente, sem a punição do homem branco (na esfera pública, isso era punido com assassinatos e linchamentos). Desse modo, hooks defende que a categoria gênero (neste caso, em referência ao privilégio masculino) permitiu aos espectadores negros entrar em um espaço imaginativo de poder falocêntrico que mediava a negação racial.

Em contraponto, o desenvolvimento da espectatorialidade para as mulheres negras foi marcado pela necessidade de criar formas de olhar e de prazer visual em um contexto que, desde os primórdios do cinema, nega o corpo feminino negro e consolida a mulher branca como passível de ser olhada e desejada, aponta a teórica. As espectadoras negras mais jovens, no entanto, percebiam os estereótipos e não se identificavam, não davam importância ao cinema. As mais velhas assumiam uma postura de subordinação, um olhar de cumplicidade e desejo, o que lhes exigia abdicar da crítica ao racismo e ao sexismo para ter prazer visual, colocando-se como passíveis de serem seduzidas, manipuladas (hooks, 1992).

Centrando sua análise no olhar oposicional, a autora questiona não apenas o conteúdo, mas também a construção do olhar sobre gênero e raça na linguagem cinematográfica e na teoria feminista do cinema. Ao ler o ensaio pioneiro de Laura Mulvey (1975) a partir de um ponto de vista que reconhece raça, hooks corrobora a iniciativa das espectadoras negras que, ausentes da construção do prazer visual ativo/masculino (homem branco) e passivo/ feminino (mulher branca), não se identificam com as representações.

Essa recusa à identificação está, segundo bell hooks (1992), em consonância com as ações de crítica, desconstrução e leitura a contrapelo (against the grain) que a teórica Annette Kuhn usa no livro The power of the image para descrever o prazer da resistência, o prazer de dizer "não", proposto pela crítica feminista ao cinema dominante. Tais ações, embora desconstruam a categoria "mulher", ainda se ancoram na feminilidade branca como modelo, em virtude de sua base psicanalítica, que não reconhece a diferença racial nem 
as espectadoras negras e sua capacidade de construir um olhar oposicional. Isso é exposto na antologia Feminism and film theory (editada por Constance Penley em 1988), na qual, embora constem fotos de atrizes negras, em nenhum dos textos a diferença racial é contemplada e o sujeito mulher em discussão é sempre branco, argumenta hooks.

Tal falha de percepção remete não apenas ao racismo, mas ao problema de estruturar a teoria feminista a partir da primazia da mulher como objeto, cujas imagens servem apenas para reafirmar o patriarcado, afirma a teórica feminista negra. Ela fundamenta tal asserção nas discussões propostas por Mary Ann Doane no artigo "Remembering women: psychical and historical construction in film theory", o qual, embora não tenha a questão racial como foco, destaca como a ênfase na categoria abstrata e totalizante de "mulher" bloqueia a teoria feminista para a compreensão das mulheres como sujeitos históricos, atravessados por diferentes marcadores sociais. Esse texto integra a antologia Psychoanalysis and cinema, editada por E. Ann Kaplan em 1990, na qual apenas um dos ensaios inclui raça como categoria de análise. Tais aspectos permitiram à crítica feminista, de acordo com hooks (1992), a produção de uma prática discursiva que ignora a representação da mulher negra e sua espectatorialidade.

A vivência das mulheres negras na estrutura social do racismo instigouIhes a capacidade de confrontar o prazer visual e desenvolver o prazer da contestação, transformando o olhar em um instrumento de poder, enfatiza bell hooks (1992). Isso não constitui, segundo ela, uma reação generalista que define as formas de espectatorialidade das mulheres negras, pois, além de um ato de resistência, trata-se de uma formação crítica.

[...] fazemos mais do que resistir. Criamos textos alternativos que não são apenas reações. Como espectadoras críticas, as mulheres negras participam de uma ampla gama de relações de olhar, procurar, contestar, resistir, revisar, interrogar, e inventar em vários níveis (hooks, 1992, p. 128, tradução nossa) ${ }^{22}$.

Sobre essa formação crítica, a autora destaca ainda a produção de cineastas negras, como Julie Dash. Ela ressalta como sua experiência crítica como espectadora foi relevante na construção de seus filmes Illusions, de 1982, e Daughters of the Dust, de 1991, que, ao colocarem uma mulher negra como protagonista, no centro da narrativa, perturbam as normas dominantes. Além

22 No original: [...] We do more than resist. We create alternative texts that are not solely reactions. As critical spectators, black women participate in a broad range of looking relations, contest, resist, revision, interrogate, and invent on multiple levels (hooks, 1992, p. 128). 
disso, essas imagens convidam a espectatorialidade negra a olhar de uma maneira diferente. Tais iniciativas

[...] não simplesmente oferecem representações diferenciadas, elas imaginam novas possibilidades transgressivas para a formulação de identidade [...]. Cinematograficamente, elas fornecem novos pontos de reconhecimento, incorporando a visão de Stuart Hall de uma prática crítica que reconhece que a identidade é constituída "não fora, mas dentro da representação", e convida-nos a ver o filme "não como um espelho de segunda ordem que nos faz refletir o que já existe, mas como forma de representação capaz de nos constituir como novos tipos de sujeitos, e, assim, permitir-nos descobrir quem somos". É essa prática crítica que permite a produção de teoria do cinema feminista que teoriza a espectatorialidade feminina negra. Olhando e olhando para trás, as mulheres negras nos envolvem em um processo pelo qual vemos a nossa história como contramemória, usando-a como uma maneira de conhecer o presente e inventar o futuro (hooks, 1992, p. 130, tradução nossa) ${ }^{23}$.

Essa capacidade das espectadoras negras de desenvolver leituras oposicionais é o foco da pesquisa de Jacqueline Bobo (1988) sobre as controvérsias causadas pela repercussão do filme The color purple (A cor púrpura, Steven Spielberg, 1985), baseado no livro homônimo da escritora negra Alice Walker ${ }^{24}$, considerado racista pela crítica e que dividiu opiniões no interior da comunidade negra.

Para alguns, o filme apresenta uma reformulação de estereótipos já existentes, especialmente a brutalidade do homem negro, o que instigou protestos e denúncias; já outros observaram algumas inovações estéticas propostas na representação das personagens femininas negras. Atenta a essa

23 No original: [...] they do not simply offer diverse representations, they imagine new transgressive possibilities for the formulation of identity [...]. Cinematically, they provide new points of recognition, embodying Stuart Hall's vision of a critical practice that acknowledges that identity is constituted 'not outside but within representation', and invites us to see film 'not as a second-order mirror held up to reflect what already exists, but as that form of representation which is able to constitute us as new kinds of subjects, and thereby enable us to discover who we are'. It is this critical practice that enables production of feminist film theory that theorizes black female spectatorship. Looking and looking back, black women involve ourselves in a process whereby we see our history as counter-memory, using it as a way to know the present and invent the future" (hooks, 1992, p. 130).

24 Lançado em 1982, o romance The color purple retrata a história de Celie, uma garota negra, semianalfabeta, que vivencia diversos tipos de violência (física, sexual e psicológica) mas, com o apoio de outras mulheres, desenvolve sua feminilidade e amor próprio. A partir dessa personagem, a escritora Alice Walker problematiza a situação degradante das mulheres negras pobres diante do racismo e do sexismo nos Estados Unidos do começo do século XX. Segundo Bobo (1988), a escritora recebeu duas importantes premiações, o American Book Award e o Prêmio Pulitzer de ficção em 1983, o que fez aumentar as vendas do romance, transformando-o em um bestseller. Ainda assim, foi somente com sua adaptação para o cinema, lançada em dezembro de 1985, que The color purpleefetivamente explode no contexto cultural norte-americano. 
conjuntura, Bobo (1988), por meio de entrevistas em grupo com espectadoras negras, examinou as maneiras como uma audiência específica cria significado a partir de uma produção dominante e usa isso para seu empoderamento pessoal e coletivo, como, por exemplo, no reconhecimento da superação da personagem Celie (Whoopi Goldberg) e a influência de Shug (Margaret Avery) nesse processo.

A pesquisadora afirma que as mulheres negras (considerando em parte suas histórias e experiências pessoais) têm descoberto algo de progressivo e útil no filme, o que contrasta com a recepção de outras/os espectadoras/ es. Tal pesquisa de recepção fílmica ancora-se no modelo encoding/decoding desenvolvido por Stuart Hall a partir de sua aplicação empírica nos estudos de David Morley, o que possibilitou novas perspectivas para a análise de audiência da mídia, pois se concentra em entender não apenas os significados do texto, mas também o enquadramento social e cultural no qual as/os espectadoras/ es estão inseridas/os, a partir do qual desenvolvem diferentes interpretações do filme. Essa leitura alternativa elaborada pelas espectadoras negras surge, segundo a autora, a partir daquilo que elas consideram estranho e que thes instiga a utilizar outras referências e pontos de vista em seus modos de recepção, e assim leem numa direção oposta, a contrapelo.

Com relação ao filme A cor púrpura, Bobo discute as escolhas de Spielberg em sua adaptação cinematográfica do romance de Walker, como a seleção de atrizes desconhecidas em detrimento de tradicionais estrelas da época, a fim de evitar a reprodução de estereótipos negativos. No entanto, segundo a autora, essa decisão consciente do diretor não impede seu filme de reforçar visões preestabelecidas, como na representação do casal Harpo e Sofia, personagens que no romance não se enquadram nos modelos de masculinidade efeminilidade vigentes, mas, no longa-metragem, constituem o alívio cômico da narrativa.

Sãomencionadospelapesquisadoravárioselementosdeintertextualidade entre o filme e representações anteriores da população negra no cinema, como o uso da técnica de montagem alternada (cross-cutting) criada por David Griffith (e empregada em seu filme O nascimento de uma nação, de 1915), que também é utilizada por Spielberg com o mesmo objetivo: retratar a natureza selvagem dos negros africanos e afro-americanos.

Essa continuidade é importante também para entender as reações positivas das espectadoras sobre o filme, pois o conhecimento prévio de representações racistas no cinema lhes possibilita filtrar o que é negativo e selecionar elementos com os quais possam se identificar, defende Jacqueline Bobo (1988, p. 186, tradução nossa), que investiga tal processo a partir dos conceitos de interpelação e interdiscurso. 


\begin{abstract}
Interpelação é a maneira pela qual o sujeito é saudado pelo texto; é o método pelo qual os discursos ideológicos constituem sujeitos e os atraem para a relação texto/sujeito. [...] O momento do encontro do texto e o sujeito é conhecido como o "interdiscurso". David Morley explica este conceito, desenvolvido por Michel Pêcheux, como o espaço, o momento específico quando sujeitos trazem suas histórias para sustentar a produção de significado em um texto. Dentro desse espaço interdiscursivo, competências culturais entram em jogo. Uma competência cultural é o repertório de estratégias discursivas, a gama de conhecimento, que um espectador traz para o ato de assistir um filme e criar significado de uma obra (Bobo, 1988, p. 186). ${ }^{25}$
\end{abstract}

A noção de competência cultural possibilitou compreender como o repertório do/a espectador/a determina sua interpretação do texto, assim como os marcadores sociais, como raça, classe e gênero, entre outros, distribuem formas diferenciadas de decodificação. Nesse sentido, a autora defende que uma pessoa marginalizada pode desenvolver leitura positiva, pois por meio da negociação constrói algo útil e/ou dá uma resposta subversiva; assim como pode rejeitar o produto cultural, o que se constitui uma leitura negativa.

Tais tipos de leituras oposicionais fundamentam-se numa experiência prévia com o conjunto de imagens negativas que historicamente são oferecidas à população negra, como nas representações do cinema. Entretanto, nesse quadro cultural intertextual, Bobo (1988) pontua também a influência da produção de escritoras negras que emerge nos anos 1970 e 1980 (como a própria Alice Walker). Ou seja, os esforços criativos no âmbito da representação, com a produção de obras literárias mais próximas das experiências, das histórias e da vida cotidiana das mulheres negras, ressoam nas práticas de recepção e espectatorialidade feminina negra, possibilitando às espectadoras negras desenvolver um envolvimento positivo com o filme $A$ cor púrpura e sustentar estratégias de decodificação, negociando os sentidos da narrativa e construindo um reconhecimento, um vínculo afetivo com a protagonista Celie e sua história de superação.

25 No original: Interpellation is the way in which the subject is hailed by the text; it is the method by which ideological discourses constitute subjects and draw them into the text/subject relationship [...]. The moment of the encounter of the text and the subject is known as the 'interdiscourse'. David Morley explains this concept, developed by Michel Pêcheux, as the space, the specific moment when subjects bring their histories to bear on meaning production in a text. Within this interdiscursive space, cultural competencies come into play. A cultural competency is the repertoire of discursive strategies, the range of knowledge that a viewer brings to the act of watching a film and creating meaning from a work [...] (Bobo, 1988, p. 186). 


\section{Considerações finais}

Problematizar os limites da teoria feminista do cinema, em especial o não reconhecimento da intersecção de gênero e raça mostra-se oportuno para se pensar não apenas a insuficiência da psicanálise como quadro conceitual para a análise das representações das mulheres na telona, mas também nos possibilita investigar as hierarquias e relações de poder nos âmbitos da produção, recepção e pesquisa/teoria.

A ênfase na diferença sexual circunscreve a compreensão de tais instâncias à condição subordinada da mulher ao homem, da personagem feminina ao masculino na ficção e no cotidiano, ou seja, na narrativa e nas formas de prazer visual, já que se ancoram na construção binária ativo versus passivo, que também rege as relações sociais. Mas de que "mulher(es)" estamos falando?

Conforme apresentado no decorrer deste artigo, historicamente a mulher branca é considerada o modelo de beleza e feminilidade, o que implica no apagamento, no não-reconhecimento de raça e sexualidade como determinantes para as práticas de representação (no cinema e nos meios de comunicação), para os modos de recepção e formas de espectatorialidade, bem como para a própria construção da teoria feminista do cinema, que somente no fim dos anos 1980 e início de 1990 começa a discutir esse privilégio branco.

Esse debate é intensificado com as contribuições do feminismo negro que, a partir da vivência das mulheres negras, destaca a necessidade de historicizar a intersecção de gênero e raça, atentando-se à forma como as personagens femininas negras são construídas e principalmente, às relações de poder existentes durante na escravização para se compreender a construção do olhar e do prazer visual. Diante da impossibilidade de olhar e posteriormente de se identificar com as representações que eram oferecidas pelo cinema (e a mídia no geral), as mulheres negras desenvolveram um olhar oposicional, que como aponta bell hooks se configura uma formação crítica, que lhes permitiu filtrar tais imagens, e a partir de seus repertórios culturais, ressignificá-las, como explicitado na pesquisa de Jacqueline Bobo, que analisa as interpretações de espectadoras negras sobre o filme $A$ cor púrpura.

O reconhecimento do aspecto racial na produção e na recepção fílmica é significativo também para se pensar sobre os regimes de visibilidade oferecidos às mulheres negras no cinema brasileiro, que pela manutenção de um padrão estético branco (embora dissimulado como mestiço), impõe a tais sujeitos sociais à condição de invisibilidade (ora pelo estereótipo, ora pela ausência), conformando assim os imaginários sobre a intersecção de gênero e raça, ainda fortemente atrelados à experiência da escravização. 


\section{REFERÊNCIAS}

BOBO, Jacqueline. The color purple: black women as cultural readers. In: PRIBRAM, Deidre. Female spectators: looking at film and television. London: Verso, 1988. p. 90-109.

BORDWELL, David. O cinema clássico hollywoodiano: normas e princípios narrativos. In: RAMOS, Fernão P. (Org.). Teoria contemporânea do cinema: documentário e narratividade ficcional. v. 2. São Paulo: Senac, 2005. p. 277-302.

GAINES, Jane. White privilege and looking relations: race and gender in feminist film theory. In: THORNHAM, Sue (Ed.). Feminist film theory: a reader. Edinburgh: Edinburgh University Press, 1999. p. 293-306.

HAYWARD, Susan. Cinema studies: the key concepts. 2 ed. London: Routledge, 2000.

hooks, Bell. The oppositional gaze. In: Black looks: race and representation. London: Turnaround, 1992. p. 115-131.

KAPLAN, Elizabeth. A mulher e o cinema: os dois lados da câmera. Tradução de Helen Marcia Potter Pessoa. Rio de Janeiro: Rocco, 1995.

MALUF, Sônia W.; MELLO, Cecilia A. de; PEDRO, Vanessa. Políticas do olhar: feminismo e cinema em Laura Mulvey. Revista Estudos Feministas, Florianópolis, v. 13, n. 2, p. 343-350, 2005. DOI: https://doi.org/10.1590/S0104-026X2005000200007.

$\mathrm{MCCABE}$, Janet. Feminist film studies: writing the woman into cinema. London: Wallflower, 2004.

MODLESKI, Tania. Cinema and the dark continent: race and gender in popular film. In: THORNHAM, Sue (Ed.). Feminist film theory: a reader. Edinburgh: Edinburgh University Press, 1999. p. 321-335.

MULVEY, Laura. Visual pleasure and narrative cinema. Screen, v. 16, n. 3, p. 6-18,1975. Prazer visual e cinema narrativo. In: XAVIER, Ismail (Org.). A. Experiência do cinema. Rio de Janeiro: Edições Graal; Embrafilme, 1983. p. 435-454.

. Reflexões sobre "Prazer visual e cinema narrativo" inspiradas por Duelo ao Sol, de King Vidor (1946). Tradução de Silvana Vieira. In: RAMOS, Fernão P. (Org.). Teoria contemporânea do cinema: pós-estruturalismo e filosofia analítica. $v$. 1. São Paulo: Senac, 2005. p. 381-392.

OLIVEIRA FILHO, José $\mathrm{H}$. O cinema narrativo, a psicanálise e o feminismo sob a perspectiva de Laura Mulvey. Revista Habitus, Rio de Janeiro, v. 10, n. 1, p. 3849, 2012. 
RIBEIRO, Djamila. Postura incômoda. Sesc 70 Anos, São Paulo, 30 jul. 2015. Disponível em: http://www.sescsp.org.br/online/artigo/9242_NOVO+FEMINISMO. Acesso em: 12 jan. 2015.

STAM, Robert. Introdução à teoria do cinema. Campinas; São Paulo: Papirus, 2003.

XAVIER, Ismail. O olhar e a cena. São Paulo: Cosac \& Naify, 2003.

O discurso cinematográfico: a opacidade e a transparência. São Paulo: Paz e Terra, 2005.

YOUNG, Lola. Fear of the dark: race, gender and sexuality in the cinema. London: Routledge, 1996a.

The rough side of the mountain: black women and representation in film. In: JARRETT-MACAULEY, Delia (Ed.). Reconstructing womanhood, reconstructing feminism: writings on black women. London: Routledge, 1996b. p. 177-202.

Recebido em: 1/3/2017

Aceito em: 23/5/2017

Dados da autora:

Ceiça Ferreira (Conceição de Maria Ferreira Silva) | ceicaferreira@gmail.com

Doutora em Comunicação pela Universidade de Brasília (UnB). Professora e pesquisadora do Curso de

Cinema e Audiovisual da Universidade Estadual de Goiás (UEG).

Universidade Estadual de Goiás - UEG

Campus Laranjeiras - Curso de Cinema e Audiovisual

Rua Prof. Alfredo de Castro, 9175 - Parque das Laranjeiras,

74855-130 - Goiânia (GO) - Brasil 